\title{
Nutrition and the Lung
}

\author{
Jatinder Bhatia Anjali Parish \\ Section of Neonatology, Department of Pediatrics, Medical College of Georgia, Augusta, Ga., USA
}

\section{Key Words}

Nutrition and the lung $\cdot$ Malnutrition - Nutrients and lung disease $\cdot$ Lung injury, growth failure $\cdot$ Nutritional support, principles

\begin{abstract}
The use of surfactant replacement, 'kinder gentler' modes of ventilation combined with prenatal corticosteroids have all played a role in improved survival rates of very-low-birthweight infants but have not reduced the prevalence of chronic lung disease. The increased rates of prematurity being observed in the United States along with the increased survival makes the overall problem of treatment of infants with established disease expensive spanning neonatology, pediatric critical care and general pediatrics and involving a myriad of specialists over the life of the surviving infant. However, none of the therapies used over the years have proven to be effective or have long-term adverse effects, nor have they been accepted as methods to prevent chronic lung disease. Although intuitively an appropriate nutritional therapy may be a useful adjunct in the care of the premature sick infant, perinatal malnutrition remains a major problem. The role of nutrition therapy in health and disease as it pertains to the lung will be reviewed.
\end{abstract}

Copyright $\odot 2009$ S. Karger AG, Basel

The use of surfactant replacement, 'kinder gentler' modes of ventilation combined with prenatal corticosteroids have all played a role in improved survival rates of very-low-birth-weight infants but have not reduced the prevalence of chronic lung disease. The increased rates of prematurity being observed in the United States along with the increased survival makes the overall problem of treatment of infants with established disease expensive spanning neonatology, pediatric critical care and general pediatrics and involving a myriad of specialists over the life of the surviving infant. Several therapies have been developed and tried over the decades: thyrotropin-releasing hormone [1], inositol [2], superoxide dismutase [3], postnatal systemic steroids [4], and inhaled corticosteroids [5], to name a few. However, none of these therapies have proven to be effective or have long-term adverse effects, nor have they been accepted as methods to prevent chronic lung disease. Although intuitively an appropriate nutritional therapy may be a useful adjunct in the care of the premature sick infant, perinatal malnutrition remains a major problem. Perinatal malnutrition augments postnatal lung injury and delays lung repair [6].

There is abundant evidence that premature infants, with and without respiratory disease, lag behind their in utero counterpart both in terms of nutritional quality and quantity leading to a nutritional deficit and growth restriction [7]. A large trial from the NICHD demonstrated that premature infants growing at the lowest quartiles developed bronchopulmonary dysplasia (BPD) more often than infants growing at the highest growth quartile, and there was a strong association between growth and neurocognitive development in follow-up studies [8] underscoring the importance of appropriate nutrition in the postnatal period. Nutrition is important to processes in-

Jatinder Bhatia

Section of Neonatology, Department of Pediatrics, Medical College of Georgia

1120 15th Street, BIW 6033

Augusta, GA 30912 (USA)

Tel. +1 706721 2331, Fax +1 706721 7531,E-Mail jatindeb@mcg.edu 
volved in normal lung development and maturation [9, 10]. Malnutrition can delay somatic growth and the development of new alveoli in addition to decreasing muscle strength, thereby prolonging the need for mechanical ventilation. In animal models, early malnutrition has been shown to alter surfactant lipid composition [11].

\section{Undernutrition and Lung Injury}

Earlier studies have demonstrated that undernutrition influences oxygen-induced toxicity. Newborn mice nursed intermittently and therefore, undernourished, were more likely to die and had more microscopic evidence of lung pathology when exposed to hyperoxia compared to their counterparts who were nursed appropriately [12]. Similarly, fasted newborn rats demonstrated increased mortality when exposed to high concentrations of oxygen $[13,14]$. Food deprivation as well as caloric restriction led to a negative influence on lung protein synthesis [15], increased weight loss and decreased DNA synthesis in lungs of mice exposed to hyperoxia [16]. The mechanisms involved in these processes including reduced survival are not clear.

The undernourished offspring with fetal growth restriction produced by limiting food intake of pregnant rats demonstrated evidence of abnormal lung maturation and reduced surfactant production. When exposed to hyperoxia, the newborn rats had decreased lung DNA and glutathione [17]. Similarly, in the premature guinea pig, starvation increased mortality with hyperoxia and there was a decrease in lung and liver glutathione content [18] suggesting the importance of glutathione reduction associated with undernutrition and its role in hyperoxiainduced lung injury. Experiments increasing glutathione in lungs resulted in decreased susceptibility to oxygeninduced lung injury. More specifically, protein-deficient rats had increased mortality with hyperoxia compared to protein-sufficient rats. Further, supplementation with cysteine, cystine or methionine as precursors of glutathione prevented the increased susceptibility to lung injury [19]. In vitro studies using cultured hamster fibroblasts where the medium was replaced every $24 \mathrm{~h}$ or withheld for the duration of the experiment demonstrated decreased evidence of hyperoxic injury in the cells where the medium was replaced. Although lack of medium replacement could have led to accumulation of toxic byproducts, it is also likely that it caused nutrient depletion and, therefore, injury. The cells provided with fresh medium had increased resistance to 4-hydroxynonenal (by product of lipid peroxidation) compared to similarly exposed cells without medium replacement [20]. Furthermore, the 4-hydroxynonenal was detoxified by glutathione [21].

There is considerable experimental evidence suggesting that lipids rich in polyunsaturated fatty acids (PUFA) are related to tolerance to hyperoxia. Lung content of PUFA in the offspring of pregnant rats reflected the diets themselves [22, 23]. Low-PUFA diets resulted in increased susceptibility to oxygen toxicity and early death and postnatal dietary manipulation produced similar results. However, the mechanism by which tolerance to hyperoxia is induced by high PUFA intake is unclear. In the presence of protein deficiency, increased PUFA intake induced lipid peroxidation in rats, and this was attributed to decreased antioxidant protection resulting from protein deficiency [24]. It is speculated that the tolerance to hyperoxia afforded by high PUFA may be related to increased pulmonary content of PUFA which might function as an antioxidant. However, there are conflicting studies (not reviewed here) that demonstrate that the unsaturated fatty acids are vulnerable to lipid peroxidation and oxidant damage. Studies of premature infants supplemented with PUFAs have not demonstrated a reduction in the incidence of chronic lung disease [25]. However, in more recent epidemiologic studies, diets high in PUFA have been associated with better 'respiratory health' in early childhood [26].

Despite the evidence of a protective effect of PUFA against oxidant injury, earlier studies with lipid administration in human infants have also produced conflicting results. Hammerman and Aramburo [27] provided premature infants with parenteral lipid emulsion on postnatal day 3 and compared them to control infants who received the emulsion later. The severity of chronic lung disease was greater in the early lipid group, whereas survival without chronic lung disease was similar in the two groups; the results may have been confounded in that the early lipid group had a 50\% higher alveolar-arterial oxygen difference on day 1 compared to controls. Subsequent studies did not demonstrate differences in respiratory morbidity by early lipid administration $[28,29]$. A metaanalysis of five studies with early administration of lipids in premature infants failed to demonstrate statistically significant benefits or adverse effects on morbidity and mortality [30]. More recent studies involving early administration of lipids and amino acids have demonstrated safety and efficacy, but chronic lung disease was not a studied outcome measure [31-35]. 


\section{Other Nutrients and Lung Disease}

It is well established that ongoing malnutrition as occurs in infants with chronic lung disease is associated with growth failure and delayed lung repair. The role of vitamin $\mathrm{A}$, which is essential for growth and differentiation of epithelial cells [36-39], has been described extensively, but its use is not widespread because of reluctance to give repeated intramuscular injections to very small infants. In the NICHD trial of 5,000 IU of vitamin A intramuscularly three times per week for 4 weeks, a modest decrease in oxygen requirement at 36 weeks' postmenstrual age without differences in home oxygen use, bronchodilator therapy or respiratory hospitalizations was reported.

Interest in vitamin $\mathrm{E}$, an antioxidant that protects cell membranes from oxidative injury, is decades old [40], but in a large trial in the presurfactant era, no differences in early death, mortality from BPD, oxygen requirement at 28 postnatal days, sepsis or necrotizing enterocolitis were demonstrated [41]. Recent studies demonstrate a correlation between low vitamin $\mathrm{E}$ and selenium levels in cord blood and on the third day of life with the development of chronic lung disease [42]. Nonetheless, more evidence is required before vitamin $\mathrm{E}$ supplementation can be recommended in premature infants.

Selenium is a constituent of endogenous glutathione peroxidase and in experimental animals, selenium deficiency is associated with increased susceptibility to oxidative lung injury. A randomized control trial of selenium supplementation in very-low-birth-weight infants from week 1 to 36 weeks' postmenstrual age did not demonstrate differences in oxygen requirement at either 28 days or 36 weeks postmenstrual age [43]. A recent Cochrane review of oral selenium supplementation did not demonstrate reduction in oxygen dependency at 28 days or total days [44]. Thus, selenium supplementation in premature infants to prevent lung injury and chronic lung disease is not routinely recommended.

Inositol, a naturally occurring lipid that is a precursor for the synthesis of pulmonary surfactant, functions as a cellular mediator of signal transduction, metabolic regulation and growth. It is involved in the shift from the production of phosphatidylinositol-rich surfactant in the immature lung to the production of phosphatidylglycerol-rich surfactant in the mature lung. On the premise that premature infants had low levels of inositol, Hallman et al. [2] supplemented the infants with inositol and demonstrated a reduction in the incidence of BPD. Metaanalysis of infants supplemented with inositol also dem- onstrated statistically significant reductions in death or BPD [45]; additional benefits of inositol supplementation have included a reduction in the incidence of retinopathy of prematurity and grade III and IV intraventricular hemorrhage [2]. Larger multicentered trials are needed to determine the role of inositol in the prevention of chronic lung disease.

Glutamine supplementation of parenteral nutrition did not decrease the incidence of chronic lung disease, late-onset sepsis or death in very small preterm infants [46]. Since glutamine is essential for glutathione and for rapidly dividing cells, it may have a role in cell proliferation especially in the presence of high levels of oxygen [47].

The deleterious effects of lipids noted earlier may be due to protection only seen in animals and not humans, overabundance of PUFAs or toxic products in lipids including products of lipid peroxidation. Trace elements such as copper, zinc and manganese may play a role in pulmonary antioxidant systems through synthesis of antioxidant enzymes - copper zinc superoxide dismutase, manganese superoxide dismutase. A multicenter randomized trial in infants $\leq 1,200$ g given recombinant human copper zinc superoxide dismutase for the first 28 days as long as the infant remained on mechanical ventilation found no differences in BPD at 28 days, BPD at 36 weeks postmenstrual age, number of oxygen days or hospital days. The incidence of BPD varied widely between centers from 10 to $61 \%$. The treated infants showed improved pulmonary status in the form of lower hospital admissions, emergency room visits and the use of medications for asthma-like symptoms measured at 1 year corrected age [48]. A similar approach was taken in a strategy to replenish glutathione stores by providing a precursor of cysteine, $\mathrm{N}$-acetylcysteine, which is also a free radical scavenger. A 6-day course of intravenous $\mathrm{N}$-acetylcysteine did not prevent death or BPD in very small preterm infants [49].

\section{Growth Failure in Lung Injury}

The etiology of growth failure and malnutrition preceding and following the development of BPD is multifactorial (table 1).

The growth failure associated with preterm delivery is compounded by factors associated with the development of chronic lung disease as outlined in table 1 . Factors associated with the initial growth failure in preterm infants and possible strategies to combat it are reviewed else- 
Table 1. Growth failure associated with preterm delivery is compounded by factors associated with the development of chronic lung disease

\begin{tabular}{ll}
\hline Issue & Cause \\
\hline Premature delivery & $\begin{array}{l}\text { Disruption of placental } \\
\text { nutrient delivery }\end{array}$ \\
\hline 'Metabolic' shock & $\begin{array}{l}\text { Delay in initiation of } \\
\text { parenteral nutrition }\end{array}$ \\
\hline Decreased nutrient intake & $\begin{array}{l}\text { Delay in initiation and } \\
\text { advancement of enteral } \\
\text { nutrition }\end{array}$ \\
\hline Decreased nutrient intake & $\begin{array}{l}\text { Fluid and, therefore, } \\
\text { energy restriction }\end{array}$ \\
\hline Feeding difficulty, oral aversion & $\begin{array}{l}\text { Suck-swallow dysfunc- } \\
\text { tion }\end{array}$ \\
\hline $\begin{array}{l}\text { Malabsorption, lack of feeding, } \\
\text { gastroesophageal reflux }\end{array}$ & $\begin{array}{l}\text { Gastrointestinal } \\
\text { dysfunction/failure }\end{array}$ \\
\hline Altered energy metabolism & $\begin{array}{l}\text { Acute and chronic } \\
\text { hypoxia and acidosis }\end{array}$ \\
\hline $\begin{array}{l}\text { Increased energy expenditure } \\
\text { decreased muscle strength; increased } \\
\text { energy expenditure }\end{array}$ & Symptomatic anemia \\
\hline $\begin{array}{l}\text { Increased energy expenditure } \\
\text { restriction secondary to high BUN } \\
\text { (decreased protein degradation) }\end{array}$ & Methylxanthines \\
\hline $\begin{array}{l}\text { Postnatal steroids } \\
\text { Undernutrition }\end{array}$ \\
\hline
\end{tabular}

where [50]. The growth deficit persists throughout the hospitalization period and growth failure rates in infants with BPD post discharge are estimated to be $30-67 \%$ [51]. The poor growth of infants with lung injury manifested as BPD is also associated with deficits in fat-free body mass and total body fat [52].

Overall goals of nutritional support for infants developing or who have developed lung injury and chronic disease remain similar to that of premature infants with special attention to several comorbidities. These include increased work of breathing thus requiring additional energy intakes to compensate; the generally used figure of an additional $25 \%$ is only an estimate. Growth rates need to be monitored and nutrition tailored to assure the best possible growth without adverse metabolic effects such as metabolic acidosis, azotemia, etc. Apart from the feeding difficulties mentioned above, these infants are also prone to develop pulmonary edema and often need fluid restriction which must be balanced with nutrient and energy needs. Routine use of diuretics as an adjunct to fluid management is not recommended since it has not shown to decrease the incidence of BPD and, in addition, has been associated with side effects including hypokalemia, hyponatremia, metabolic acidosis, hypercalciuria with nephrocalcinosis, and hypochloremia [53].

\section{Principles of Nutritional Support}

The principles of nutritional support are as follows:

(1) Aggressive parenteral nutrition initiation and advancement. This practice has been shown to allow infants to achieve positive nitrogen balance from the first day of life, improve amino acid profiles and demonstrate improved growth during hospitalization.

(2) Early initiation of enteral nutrition, when feasible.

(3) Protein and energy intakes to support best growth possible. Very preterm infants are often catabolic early in life. While the traditional focus is respiratory and cardiac support, full nutritional support is often delayed and glucose is the only nutrient provided to support normoglycemia. Rats provided decreased energy intake in the first few weeks of life have been shown to have lower lung weights, reduced number of alveoli and lower stores of pulmonary surfactant as adults [56]. Lipids are often held or provided in small quantities in the first few days of life because of unsubstantiated concerns regarding hyperbilirubinemia and the risk of kernicterus. In infants receiving fat-free intravenous nutrition, there is a correlation between glucose intake and $\mathrm{CO}_{2}$ production. Providing excessive intravenous glucose beyond the neonatal glucose oxidative capacity of about $12 \mathrm{mg} / \mathrm{kg} / \mathrm{min}$ can potentially result in increased oxygen consumption, energy expenditure and $\mathrm{CO}_{2}$ production. Infants with BPD have higher basal oxygen consumption, increased energy expenditure and basal $\mathrm{CO}_{2}$ production. Yunis and $\mathrm{Oh}$ [55] demonstrated that subjecting these infants to glucose infusions of $12 \mathrm{mg} / \mathrm{kg} / \mathrm{min}$ causes a rise in energy expenditure, oxygen consumption and $\mathrm{CO}_{2}$ production. High-fat formulas have not demonstrated significant changes in $\mathrm{pCO}_{2}$ or respiratory outcomes.

(4) Careful attention to fluid balance and adjunctive strategies to minimize lung injury such as surfactant replacement, avoidance/minimize volutrauma and/or barotrauma, and minimize oxygen use to maintain oxygen saturations appropriate for gestational age. 
(5) Feeding formulas appropriate for premature infants or fortified human milk.

(6)Attention to feeding difficulties and involvement of lactation consultants and speech therapists as appropriate.

(7)Diagnosis and management of gastroesophageal reflux and gastroesophageal reflux disease.

(8) Careful follow-up and appropriate nutritional management post discharge. This includes attention to the development of metabolic bone disease (use of diuretics, unfortified human milk, and decreased vitamin D intake). Aggressive treatment of 'pulmonary' infections, reactive airway disease and appropriate respiratory syncytial virus vaccination.
In summary, the nutritional support of the preterm infant susceptible to lung injury and development of chronic lung injury should begin before delivery to prevent growth restriction and continue throughout the period of hospitalization and beyond [56]. The use of nutrients to enhance protection against oxidative injury has not provided the benefits expected and needs more study. Vitamin A supplementation has been demonstrated to provide modest benefit. Nutritional therapy providing adequate protein, energy and micronutrients, including calcium, phosphorus and vitamin $\mathrm{D}$, is of paramount importance to promote optimal postnatal growth and longterm development, both pulmonary and neurocognitive.

\section{References}

-1 Ballard RA, Ballard PL, Creasy RK, Padbury J, Polk DH, Bracken M, Moya FR, Gross I, TRH Study Group: Respiratory disease in very-low-birth-weight infants after prenatal thyrotropin-releasing hormone and glucocorticoid. Lancet 1992;339:510-515.

2 Hallman M, Bry K, Hoppu K, Lappi M, Pohjavuori M: Inositol supplementation in premature infants with respiratory distress syndrome. N Engl J Med 1992;326:1233-1239.

-3 Rosenfeld WN, Davis JM, Parton L, Richter SE, Price A, Flaster E, Kassem N: Safety and pharmacokinetics of recombinant human superoxide dismutase administered intratracheally to premature neonates with respiratory distress syndrome. Pediatrics 1996; 97:811-817.

4 American Academy of Pediatrics: Postnatal corticosteroids to treat or prevent chronic lung disease in preterm infants. Pediatrics 2002;109:330-338.

5 Grneck P, Goetze-Speer B, Speer CP: Effects of inhaled beclomethasone compared to systemic dexamethasone on lung inflammation in preterm infants at risk of chronic lung disease. Pediatr Pulmonol 1999;27:383-387.

6 Frank L: Antioxidants, nutrition, and bronchopulmonary dysplasia. Clin Perinatol 1992;19:541-562.

7 Clark RH, Thomas P, Peabody J: Extrauterine growth restriction remains a serious problem in prematurely born neonates. Pediatrics 2003;111:986-990.

-8 Ehrenkranz RA, Dusick AM, Vohr BR, Wright LL, Wrage LA, Poole WK: Growth in the neonatal intensive care unit influences neurodevelopmental and growth outcomes of extremely low birth weight infants. Pediatrics 2006;117:1253-1261.

$\$ 9$ Curle DC, Adamson IYR: Retarded development of neonatal rat lung by maternal malnutrition. J Histochem Cytochem 1978;26: 401-408.
10 Kelly FJ, Fussell JC, Postle TD: Effect of acute food restriction on pulmonary growth and protein turnover in preterm guinea pigs. Am J Physiol 1992;262:E240-E245.

-11 Guarner V, Tordet C, Bourbon JR: Effects of maternal protein-calorie malnutrition on the phospholipid composition of surfactant isolated from fetal and neonatal rat lungs. Compensation by inositol and lipid supplementation. Pediatr Res 1995;37:783-788.

$\checkmark 12$ Polgar G, Antagnoli W, Ferrigan LW, Martin EA, Gregg WP: The effect of chronic exposure to $100 \%$ oxygen in newborn mice. Am J Med Sci 1966;252:580-587.

13 Bucher JR, Roberts RJ: Alpha-tocopherol (vitamin E) content of lung, liver, and blood in the newborn rat and human infant: influence of hyperoxia. J Pediatr 1981;98:806811.

14 Frank L, Groseclose E: Oxygen toxicity in newborn rats: the adverse effects of undernutrition. J Appl Physiol 1982;53:12481255.

15 Massaro D: Hyperoxia: influence of food deprivation on protein synthesis by lung. Proc Soc Exp Biol Med 1973;143:602-603.

16 Hackney JD, Evans MJ, Bils RF, Spier CE, Jones MP: Effects of oxygen at high concentrations and food deprivation on cell division in lung alveoli of mice. Exp Mol Pathol 1977;26:350-358.

17 Frank L, Lewis PL, Garcia-Pons T: Intrauterine growth-retarded rat pups show increased susceptibility to pulmonary $\mathrm{O}_{2}$ toxicity. $\mathrm{Pe}$ diatr Res 1986;20:505-510.

18 Langley SC, Kelly FJ: Effect of food restriction on hyperoxia-induced lung injury in preterm guinea pigs. Am J Physiol 1992;263: L357-L362.

19 Deneke SM, Gershoff SN, Fanburg BL: Potentiation of oxygen toxicity in rats produced by dietary or amino acid deficiency. J Appl Physiol 1983;54:147-151.
20 Sullivan SJ, Roberts RJ, Spitz DR: Replacement of media in cell culture alters oxygen toxicity: possible role of lipid aldehydes and glutathione transferases in oxygen toxicity. J Cell Physiol 1991;147:427-433.

-21 Spitz DR, Sullivan SJ, Malcolm RR, Roberts RJ: Glutathione dependent metabolism and detoxification of 4-hydroxy-2-nonenal. Free Radic Biol Med 1991;11:415-423.

-22 Sosenko IRS, Innis SK, Frank L: Polyunsaturated fatty acids and protection of newborn rats from oxygen toxicity. J Paediatr 1988; 112:630-637.

-23 Sosensko IRS, Innis SK, Frank L: Menhaden fish oil, $n-3$ polyunsaturated fatty acids and protection of newborn rats from oxygen toxicity. Pediatr Res 1989;25:399-404.

24 Huang CJ, Fwu ML: Protein insufficiency aggravates the enhanced lipid peroxidation and reduced activities of antioxidative enzymes in rats fed diets high in polyunsaturated fat. J Nutr 1992;122:1182-1189.

25 Clandinin J, Van Aerde K, Merkel KL, et al: Growth and development of preterm infants fed infant formulas containing docosahexaenoic acid and arachidonic acid. J Pediatr 2005; 146:461-468.

26 Birch EE, Castañeda YS, Wheaton D, et al: Visual maturation of term infants fed longchain polyunsaturated fatty acid-supplemented or control formula for 12 months. Am J Clin Nutr 2005;81:871-879.

27 Hammerman C, Aramburo MJ: Decreased lipid intake reduces morbidity in sick premature infants. J Pediatr 1988;113:1083-1088.

28 Gilberston N, Kovar IZ, Cox DJ, Crowe L, Palmer NT: Introduction of intravenous lipid administration on the first day of life in the very low birth weight neonate. J Pediatr 1991;119:615-623. 
-29 Alwaidh MH, Bowden L, Shaw B, Ryan SW: Randomised trial of effect of delayed intravenous lipid administration on chronic lung disease in preterm neonates. J Pediatr Gastroenterol Nutr 1996;22:303-306.

30 Summer K, Rao SC: Early introduction of lipids to parenterally-fed preterm infants. Cochrane Database Syst Rev 2005;2: CD005256.

>31 Wilson DC, Cairns P, Halliday HL, Reid M, McClure G, Dodge JA: Randomized controlled trial of an aggressive nutritional regimen in sick very low birth weight infants. Arch Dis Child Fetal Neonatal Ed 1997;77: 4-11.

\$2 Ibrahim HM, Jeroudi MA, Baier RJ, Dhanareddy R, Krouskop RW: Aggressive early total parenteral nutrition in low-birthweight infants. J Perinatol 2004;24:482486.

>33 Thureen PJ, Melara D, Fennessey PV, Hay WW: Effect of low versus high intravenous amino acid intake on very low birth weight infants in the early neonatal period. Pediatr Res 2003;53:24-32.

-34 Te Braake FWJ, van den Akker CHP, Wattimena DJL, Huijmans JG, van Goudoever JB: Amino acid administration to premature infants directly after birth. J Pediatr 2005; 147: 457-461.

>35 Poindexter BB, Langer JC, Dusick AM, Ehrenkranz RA: NICHD neonatal research Network. Early provision of parenteral amino acids in extremely low birth weight infants: relation to growth and neurodevelopmental outcome. J Pediatr 2006;148:300305.

\36 Tyson JE, Wright LL, Oh W, Kennedy KA, Mêlée I, Ehrenkranz RA: Vitamin A supplementation for extremely-low-birth-weight infants. National Institute of Child Health and Human Development Neonatal Research Network. N Engl J Med 1999;340: 1962-1968.
37 Ambalavaran N, Tyson JE, Kennedy KA, Hansen NI, Vohr BR, Wright LL, et al: Vitamin A supplementation for extremely low birth weight infants: outcome at 18-22 months. Pediatrics 2005;115:e249-e254.

38 Ambalavaran N, Wu TJ, Tyson JE, Kennedy KA, Roane C, Carlo WA: A comparison of three vitamin A dosing regimens in extremely-low-birth-weight infants. J Pediatr 2003; 142:656-661.

39 Kennedy KA, Stoll BJ, Ehrenkranz RA, et al: Vitamin A to prevent bronchopulmonary dysplasia in very-low-birth-weight infants: has the dose been too low? The NICHD Neonatal Research Network. Early Hum Dev 1997;49:19-31.

40 Ehrenkranz RA, Ablow RC, Warshaw JB: Effect of vitamin E on the development of oxygen-induced lung injury in neonates. Ann NY Acad Sci 1982;393:452-466.

41 Watts JL, Milner R, Zipursky A, Paes B, Ling E, Gill G, et al: Failure of supplementation with vitamin $\mathrm{E}$ to prevent bronchopulmonary dysplasia in infants less than 1,500 $\mathrm{g}$ birth weight. Eur Respir J 1991;4:188-190.

-42 Falciglia HS, Johnson JR, Sullivan J, et al: Role of antioxidant nutrients and lipid peroxidation in premature infants with respiratory distress syndrome and bronchopulmonary dysplasia. Am J Perinatol 2003;20. 97-107.

43 Darlow BA, Winterbourn CC, Inder TE, Graham PJ, Harding JE, Weston PJ, et al: The effect of selenium supplementation on outcome in very low birth weight infants: a randomized controlled trial. The New Zealand Neonatal Study Group. J Pediatr 2000;136: 473-480.

44 Darlow BA, Austin NC: Selenium supplementation to prevent short-term morbidity in preterm neonates. Cochrane Database Syst Rev 2003;4:CD003312.

45 Howlett A, Ohlsson A: Inositol for respiratory distress syndrome in preterm infants. Cochrane Database Syst Rev 2003; 4: CD000366.

-46 Poindexter BB, Ehrenkranz RA, Stoll RJ, et al: Parenteral glutamine supplementation does not reduce the risk of mortality or late onset sepsis in extremely low birth weight infants. Pediatrics 2004;113:1209-1215.
47 Ogunlesi F, Cho C, McGath-Morrow SA: The effect of glutamine on A549 cells exposed to moderate hyperoxia. Biochim Biophys Acta 2004;1688:112-120.

-48 David JM, Parad RB, Michele T, Allred E, Pric A, Rosenfeld W, et al: Pulmonary outcome at 1 year corrected age in premature infants treated at birth with recombinant human CuZn superoxide dismutase. Pediatrics 2003; 111:469-476.

49 Ahola T, Lapatto R, Raivio KO, et al: N-Acetylcysteine does not prevent bronchopulmonary dysplasia in immature infants: a randomized controlled trial. J Pediatr 2003;143: 713-719.

50 Parish A, Bhatia J: Early aggressive nutrition in the premature infant. Neonatology 2008; 94:211-214.

51 Johnson DB, Cheney C, Monsen ER: Nutrition and feeding in infants with bronchopulmonary dysplasia after initial hospital discharge: risk factors for growth failure. J Am Diet Assoc 1998;98:649-656.

52 Huysman WA, de Ridder M, de Bruin NC, et al: Growth and body composition in preterm infants with bronchopulmonary dysplasia. Arch Dis Child Fetal Neonatal Ed 2003;88: F46-F51.

53 Kao LC, Durand DJ, McCrea RC, Birch M, Powers RJ, Nickerson BG: Randomized trial of long-term diuretic therapy in infants with oxygen-dependent bronchopulmonary dysplasia. J Pediatr 1994;124:772-781.

54 Van Aerde JEE, Narvey M: Acute respiratory failure; in Thureen PJ, Hay WW (eds): Neonatal Nutrition and Metabolism, ed 2. New York, Cambridge University Press, 2006, pp 508-521.

55 Yunis KA, Oh W: Effects of intravenous glucose loading on oxygen consumption, carbon dioxide production, and resting energy expenditure in infants with bronchopulmonary dysplasia. J Pediatr 1989;115:127-132.

56 Bhatia J: Early nutritional support of the very low birth weight infant in the NICU. J Neonatol 2006;20:272-274. 